\title{
Assessment of Medical Students' Attitudes Towards Research and Perceived Barriers
}

\author{
Alaa Althubaiti, Bashayer Al Muqbil,2 Doaa Al Buraikan.2
}

\begin{abstract}
Background: Health research has been integrated as part of the curriculum of many health sciences teaching universities. The aim of this study is to measure the attitude of medical students towards research. Methods: A cross-sectional survey study was conducted from March to May 2016 using the Student Attitude Towards Research (SAR) scale. The survey was distributed amongst undergraduate medical students at the College of Medicine, King Saud bin Abdul-Aziz University for Health Sciences, Riyadh, Saudi Arabia. Our main outcome measure was score on attitude scale with 15 Likert-type statements. Results: A total of 237 responses were collected from the students ( $55.6 \%$ males and $44.3 \%$ females). In general, students agreed that 'research is important for identifying and investigating problems in a subject matter' $(\mathrm{N}=206,86.9 \%)$. Female students showed significantly more positive attitude towards research $\left(P_{<0} 0.05\right)$. With regards to the degree of involvement of the faculty in the research program, $35 \%$ of students agreed that it was acceptable, and $48.1 \%$ agreed that the faculty members have adequate skills to handle research methodology. Conclusion: Most of the surveyed students were aware of the importance of undertaking medical research, but their attitude to the field was not always positive. There is an urgent need to introduce research programs as a part of the curriculum of all medical colleges and ensure that these programs meet their goals and continue to be improved by providing good infrastructural facilities in order to provide skillful physicians to support research related activities.
\end{abstract}

Key Words: Research, Medical students, Attitude, Perception (Source: MeSH-NLM).

\section{Introduction}

Different fields of health research have led to significant discoveries, the development of new therapies, and a remarkable improvement in health care and public health.' Health research has been integrated as part of the curriculum of many health sciences teaching universities, in which the students are required to carry out one research project throughout their studies. ${ }^{2-4}$ The purpose is to provide short, in-depth scholarly projects in order to nurture student's academic individuality. Such programs may give students the opportunity to become familiar with research methodology, and to explore the world of biomedical research, ranging from basic, community-oriented research to the more sophisticated clinical sciences. The students are also often encouraged to seek out the area of medical research they find most exciting and promising, and to work with a faculty member who they feel will provide the best educational experience. 5

It is important to collect and evaluate the medical student opinions towards research as it will determine the outcome of the research itself as well as demonstrating the association between the research program and the medical education. $6-8$ In the previous studies, research had a positive impact on the student motivation, and even on the doctors who had participated in a scientific program during their academic career as they would make more precise diagnoses.5,9-12 It will explore the barriers which researchers mainly face such as inadequate research training, uncertainty about completing the research successfully, the limited access to the data sources (i.e. internet) and equipment, lack of knowledge about study design and interpretation of the study results and limitation in the funding support.5, 9-12

However, the attitude of medical students towards research is rarely measured, and it has not been the focus of investigation as the research method has. Only a few studies have been done to measure the medical students' attitude towards research and different measures were used. The primary aim of this study is to measure the attitude of medical students towards health research by using an appropriate questionnaire tool.

\section{Methods}

\section{The Questionnaire}

In this study, the students' attitude towards research (SAR) scale was used. 9 It is structured in a fashion that would allow the results to be interpreted in the light of national and international recommendations. The SAR scale has been developed and tested for reliability and validity in Dammam University. Permission to use SAR scale was obtained from the developers. Students were asked to indicate their level of agreement with statements that describe attitudes towards research. Responses were categorized as 'strongly disagree $=1$ ', 'disagree $=2$ ', 'neutral=3', 'agree $=4$ ', and 'strongly agree $=5$ '. SAR scale consists of 15 items related to three different attitude subscales, as follows: (a) Attitude of students to the research activities offered in the college, (b) students' opinion of faculty involvement in research, and (c) students' opinion of the infrastructural facilities offered by the college for research. Demographics information (age, year of study, gender, number of publications, number of research projects being implemented, stream number) were collected.

\section{Data Collection, Participants and Setting}

This was a cross-sectional study conducted at the College of Medicine, King Saud bin Abdulaziz University for Health Sciences, Saudi Arabia. The questionnaires were distributed in the period March 2016 to May 2016 amongst undergraduate medical students. The estimated population is 600 students. Therefore, with a margin of error of $5 \%$, and a confidence level of $95 \%$, the minimum recommended sample size is 235. Assume that the non-response rate is $20 \%$, the final sample size is 294 students. Approval to conduct the survey was obtained from the

\footnotetext{
PhD, Associate Professor, Department of Basic Medical Sciences, College of Medicine, King Saud bin Abdulaziz University for Health ScienceslKing Abdullah International Medical Research Centre, Riyadh, Saudi Arabia.

2 Medical student, College of Medicine, King Saud Bin Abdulaziz University for Health Sciences, Riyadh, Saudi Arabia.
}

Correspondence:

Alaa Althubaiti 
Institutional Review Board of King Abdullah International Medical Research Centre.

\section{Statistical Analysis}

Data were entered into the IBM SPSS Statistics for Windows version 22.0 (IBMCorp, Armonk, NY, USA). The data were cleaned and missing data were removed from the analysis. Descriptive statistics are presented as the means \pm standard deviations for numerical variables and as frequencies with percentages for categorical variables. The chi-squared test and Fisher's exact test (two-tailed), were used to compare and report differences in categorical variables. An independent samples $t$ test was used to compare continuous data. A $P$ value $<0.05$ was considered to be statistically significant.

\section{Results}

\section{Student Characteristics}

The total number of student responses was 237. Among the sample 132 (55.6\%) of the respondents were male students and $105(44.3 \%)$ were female. Most of the students $127(53.6 \%)$ had a GPA of 4.5 to 5 Response rates were $175(73.8 \%)$ from pre-clinical phase and $62(26.2 \%)$ from clinical phase students. Most of the students have not published research before 224 (94.5\%). Characteristics of the participants are presented in Table 1.

Table 1. The Research Medical Students' Characteristics.

\begin{tabular}{lc}
\hline Characteristics & $\begin{array}{c}\text { Descriptive } \\
\text { statistics }\end{array}$ \\
Age, years [mean \pm standard deviation] & $21.5 \pm 0.82$ \\
Sex [n (\%)] & \\
Male & $132(55.7)$ \\
Female & $105(44.3)$ \\
GPA [n (\%)] & $7(3.0)$ \\
$3-3.5$ & $26(11.0)$ \\
$3.5-4$ & $77(32.5)$ \\
$4-4.5$ & $127(53.6)$ \\
$4.5-5$ & $175(73.8)$ \\
Phase of study [n (\%)] & $62(26.2)$ \\
Pre-clinical phase & \\
Clinical phase & $13(5.5)$ \\
Have you published research before [n (\%)] & $224(94.5)$ \\
Yes &
\end{tabular}

Legend: Total number of participants $=237$. Data are given as number (percentage) for each group or mean \pm standard deviation. CPA is grade point average.

\section{Perceived Barriers and Attitudes}

Table 2 summarizes the percentage of students who expressed agreement, as measured by ratings of "agree" and "strongly agree" with statements regarding their attitudes towards research. Most of the students $206(86.9 \%)$ agreed that research is important for identifying and investigating problems in a subject matter. Only 45 (19\%) of students agreed that they always have the chance to discuss scientificlacademic research in class. In total, $89(37.6 \%)$ students agreed that they have been exposed to basic and advanced statistical tools needed for preparation of research report. Female students were significantly more interested in participating in research activities at the undergraduate level than male students (3.31 .85 vs. $2.99 \pm 1.21$; $\mathrm{P}=.017)$.

Majority of the students $133(56.1 \%)$ agreed that the college gives priority to the inclusion of undergraduates in research activities, while $102(43 \%)$ agreed that the college provides good infrastructural facilities (i.e. laboratory) needed to conduct research at the undergraduate level, and only $56(23.6 \%)$ agreed that the library facilities in the college are sufficient to conduct research. With regards to the degree of involvement of the faculty in the research program, 128 (54\%) agreed that it was good, and $114(48.1 \%)$ agreed that the faculty members have adequate skills to handle research methodology. Majority of the students $(41.8 \%)$ neither agreed nor disagreed that the funding that the university offers for the conduct of research is sufficient. Significant differences were found in the agreement levels between male and female students in terms of the adequacy of infrastructure in the college to organize research programs, as females agreed more than males $(2.30 \pm 1.16$ vs $1.93 \pm 1.19 ; P=.019)$.

Female students also agreed more than males that the faculty members do not have sufficient time to mentor undergraduate students in

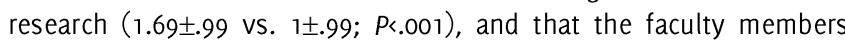
place great emphasis on research (2.70 \pm 0.89 vs. $2.41 \pm 0.97 ; P=.016)$.

Moreover, female students agreed more than males' students that faculty members use research findings as a part of their teaching material $(2.37 \pm 1.03$ vs. $1.89 \pm 1.00 ; P<.001)$. On the other hand, the disagreement levels of female students were significantly higher than male students in regard to the discussion of the faculty members of their own research interests in class ( $1.80 \pm 0.92$ vs. $1.49 \pm 0.92 ; P=.011)$.

\section{Discussion}

Assessment of medical students' attitudes towards research is an important aspect of the educational process because it shows the association between the research program and the medical education. To our knowledge, only a few studies measuring the medical students' attitude towards research have been conducted and different measures were used in each. ${ }^{13,15-17}$ Since the medical students' attitude towards health research has not been evaluated before, this study aimed to measure the attitude of medical students at King Saud bin Abdulaziz University for Health sciences towards health research by using a validated survey tool. The study revealed several characteristics of research attitudes amongst the medical students. Most of the students agree on the importance of the research for identifying and investigating problems in a subject matter, potentially due to the fact that the college has established a medical research program as part of the curriculum.

A gender difference regarding attitude towards research was also seen. This is due to the fact that although both female and male students are enrolled in the same program, female and male students are segregated and different instructors and coordinators are assigned to each group.

We compared between male and female students' attitudes, and we found that female students significantly had higher agreement on that faculty members do not have sufficient time to monitor undergraduate medical students on research. In addition, female students had a higher agreement and much more interest in participating in research activities. The skills of faculty members and their mentoring approach affect the students' attitudes towards research. ${ }^{1824}$ Therefore, continued training programs for the faculties are needed to ensure more positive students' attitudes towards research.

The primary limitation of this study is the low response rate among the students. In addition, the findings were based on responses from a self-administered web-based anonymous survey because the coinvestigators had limited time to distribute a paper-based survey for both male and female students in different batches at different colleges and self-report bias may have existed. ${ }^{25}$ This study is a one-time view of student experiences in a medical research program at a single university. Future studies that include students from multiple universities could provide better insight to the students' attitude towards medical research and common barriers. Table 2. Students Attitudes Towards Research, Comparison between Sex using Mean-level Differences. 


\begin{tabular}{|c|c|c|c|c|}
\hline Questionnaire items & $\begin{array}{l}\text { All students } \\
\text { Agreement (\%) }\end{array}$ & $\begin{array}{c}\text { Male } \\
\text { (mean } \pm s d)\end{array}$ & $\begin{array}{c}\text { Female } \\
(\text { mean } \pm s d)\end{array}$ & ${ }^{*} p$-value \\
\hline $\begin{array}{l}\text { Faculty members do not have sufficient time to mentor undergraduate } \\
\text { students in research }\end{array}$ & 56.6 & $1.0 \pm .99$ & $1.69 \pm .99$ & $<.001$ \\
\hline $\begin{array}{l}\text { I am interested in participating in research activities at the } \\
\text { undergraduate level }\end{array}$ & 78.5 & $2.99 \pm 1.21$ & $3.31 \pm .85$ & .017 \\
\hline $\begin{array}{l}\text { My college organizes and gives priority to include undergraduates in } \\
\text { research activities }\end{array}$ & 56.1 & $2.45 \pm 1.11$ & $2.56 \pm .98$ & .406 \\
\hline Faculty members have adequate skills to handle research methodology & 48.1 & $2.16 \pm 1.15$ & $2.40 \pm 0.88$ & .069 \\
\hline The degree of involvement of the faculty program is good & 54 & $1.92 \pm 1.11$ & $2.56 \pm .98$ & .153 \\
\hline Our college has adequate infrastructure to organize research programs & 43 & $1.93 \pm 1.19$ & $2.30 \pm 1.16$ & .019 \\
\hline $\begin{array}{l}\text { I have been exposed to basic and advanced statistical tools needed for } \\
\text { preparation for research report }\end{array}$ & 37.5 & $1.92 \pm 1.13$ & $1.96 \pm 1.07$ & .755 \\
\hline Faculty members place great emphasis on research & 57.3 & $2.41 \pm .97$ & $2.70 \pm .89$ & .016 \\
\hline Faculty members discuss their own research interests in class & 16.9 & $1.49 \pm .92$ & $1.80 \pm .92$ & .011 \\
\hline $\begin{array}{l}\text { Faculty members use research findings as a part of their teaching } \\
\text { material }\end{array}$ & 40.1 & $1.89 \pm 1.00$ & $2.37 \pm 1.03$ & $<.001$ \\
\hline $\begin{array}{l}\text { Research is important for identifying and investing problems in a subject } \\
\text { matter }\end{array}$ & 86.9 & $3.24 \pm .76$ & $3.30 \pm .76$ & .532 \\
\hline I always get the chance to discuss scientificlacademic research in class & 19 & $1.68 \pm .98$ & $1.60 \pm .87$ & .502 \\
\hline $\begin{array}{l}\text { Our college provides good infrastructural facilities (i.e. laboratory) } \\
\text { needed to conduct research at the undergraduate level }\end{array}$ & 23.6 & $2.02 \pm 1.01$ & $2.16 \pm 1.06$ & .464 \\
\hline $\begin{array}{l}\text { The library facilities available in my college are sufficient for us to } \\
\text { conduct research }\end{array}$ & 33.8 & $1.98 \pm 1.19$ & $1.77 \pm 1.20$ & .171 \\
\hline Sufficient funding is offered by the university for the conduct of research & 33.3 & $2.02 \pm 1.01$ & $2.16 \pm 1.06$ & .302 \\
\hline
\end{tabular}
at the undergraduate level

Legend: Total number of participants=237. Agreement = responses of "agree" or "strongly agree". *Independent sample t-test.

Despite these limitations, it is important to highlight that answering this anonymous web-based survey may have helped the participants to be more honest about their responses. Further studies are recommended to survey the attitudes of medical students from all medical schools in the country. Results can be compared with our findings, particularly since King Saud bin Abdul Aziz University for Health Sciences has a medical research program as part of the curriculum ${ }^{15,26}$ and may have had greater research-related resources than other universities in the country.

\section{Conclusion}

Most of the surveyed medical students were aware of the importance of undertaking medical research to identify, investigate and manage clinical problems. We recommend creating strategies to strengthen medical research programs worldwide. This includes introducing medical research programs as a part of the curriculum of all medical colleges and ensuring that these programs effectively meet their goals and continue to be improved by providing suitable infrastructural facilities necessary to conduct research at the undergraduate level. 


\section{References}

1. Nass S J, Levit L A. The value, importance, and oversight of health research. Beyond the HIPAA Privacy Rule: Enhancing Privacy, Improving Health Through Research. Institute of Medicine (US) Committee on Health Research and the Privacy of Health Information: The HIPAA Privacy Rule; Nass SJ, Levit LA, Costin LO, editors. Washington (DC): National Academies Press (US); 2009.

2. Hunskaar S, Breivik J, Siebke M, Tømmerås K, Figenschau K, ¿ Hansen J-B. Evaluation of the medical student research programme in Norwegian medical schools. A survey of students and supervisors. BMC Medical Education. 2009; 9(1): 43 . http://dx.doi.org/10.1186/1472-6920-9-43

3. Hren D, Lukic IK, Marusic A, Vodopivec I, Vujaklija A, Hrabak M, ¿ Marusic'M Teaching research methodology in medical schools: students' attitudes towards and knowledge about science. Medical Education. 2004; 38(1): 81-86. http://dx.doi.org/10.1111/j.1365-2923.2004.01735.x

4. Burgoyne LN, O'Flynn S, \& Boylan GB. Undergraduate medical research: the student perspective. Medical Education Online. 2010; 15(0): 5212. http://dx.doi.org/10.3402/me0.v15i0.5212

5. Al-Hilali SM, Al-Kahtani E, Zaman B, Khandekar R, Al-Shahri A, At Edward DP. Attitudes of Saudi Arabian Undergraduate Medical Students towards Health Research. Sultan Qaboos University Medical Journal. 2016; 16(1): e68-73. Available at: http://doi.org/10.18295/squmj.2016.16.01.012

6. Solomon SS, Tom SC, Pichert J, Wasserman D, a Powers AC. Impact of medical student research in the development of physician-scientists. Journal of Investigative Medicine. 2003; 51(3):149-156.

7. Jacobs $C D$, Cross PC. The value of medical student research: the experience at Stanford University School of Medicine. Medical Education. 1995; 29(5): 342-346. http://dx.doi.org/10.1111/j.1365-2923.1995.tboo023.x

8. Fisher WR. Medical student research: a program of self-education. Journal of Medical Education. 1981; 56(11): 904-908.

9. Al-Kuwaiti AA. Health science students' attitude towards research training programs in the Kingdom of Saudi Arabia: Reliability and validity of the questionnaire instrument. Journal of Family at Community Medicine. 2014; 21(2): 134-8. Available at: http://doi.org/10.4103/2230-8229.134775

10. Memarpour M, Fard AP, a Chasemi R. Evaluation of attitude to, knowledge of and barriers toward research among medical science students. Asia Pacific Family Medicine. 2015; 14(1): 1-7. Available at: http://doi.org/10.1186/s12930-015-0019-2

11. Siemens DR, Punnen S, Wong J, at Kanji N. A survey on the attitudes towards research in medical school. BMC Medical Education. 2010; 10 (4). Available at: http://doi.org/10.1186/1472-6920-10-4

12. AlChamdi KM, Moussa NA, AlEssa DS, AlOthimeen N, at Al-Saud AS. Perceptions, attitudes and practices toward research among senior medical students. Saudi Pharmaceutical Journal. 2014; 22(2): 113-117. Available at: http://doi.org/10.1016/j.jsps.2013.02.006
13. Kalén S, Stenfors-Hayes T, Hylin U, Larm MF, Hindbeck H, à Ponzer S. Mentoring medical students during clinical courses: a way to enhance professional development. Medical Teacher. 2010; 32(8): e315-e321. Available at: http://doi.org/10.3109/01421591003695295

14. Buddeberg-Fischer B, Herta KD. Formal mentoring programmes for medical students and doctors - A review of the Medline literature. Medical Teacher. 2006; 28 248-257

15. Althubaiti A. Undergraduate Medical Research Programme: A Cross-Sectional Study of Students' Satisfactions, Perceived Challenges, and Attitudes. Clobal Journal of Health Science. 2015; 7(5). Available at: http://dx.doi.org/10.5539/gjhs.v7n5p117

16. Wayne P, Hammerschlag R, Cerman J, Chapman T. Attitudes and interests toward research among students at two colleges of acupuncture and Oriental medicine. Explore (New York, NY). 2010;6(1):22-28. doi:10.1016/j.explore.2009.10.003.

17. De Oliveira NA, Luz MR, Saraiva RM, ¿t Alves LA. Student views of research training programmes in medical schools. Medical Education. 2011; 45(7): 748-755.

18. Noorelahi MM, Soubhanneyaz AA, Kasim KA. Perceptions, barriers, and practices of medical research among students at Taibah College of Medicine, Madinah, Saudi Arabia. Advances in Medical Education and Practice. 2015;6:479-485. doi:10.2147/AMEP.S83978.

19. Griffin MF, Hindocha S. Publication practices of medical students at British medical schools: experience, attitudes and barriers to publish. Med Teach. 2011;33(1):e1-e8.

20. Alsayed N, Eldeek B, Tayeb S, Ayuob N, Al-Harbi A. Research practices and publication obstacles among interns at King Abdulaziz University Hospital, Jeddah, Saudi Arabia, 2011-2012. J Egypt Public Health Assoc. 2012;87(3-4):64-70.

21. Ciri PA, Bangal VB, Phalke DB. Knowledge, attitude and practices towards medical research amongst the postgraduate students of Pravara Institute of Medical Sciences University of Central India. J Fam Med Prim care. 2014;3(1):22-24.

22. Vujaklija A, Hren D, Sambunjak D, et al. Can teaching research methodology influence students' attitude toward science? Cohort study and nonrandomized trial in a single medical school. J Investig Med. 2010;58(2):282-286.

23. Khamis N, Ibrahim R, Fetyani DM. Assessment of the research-oriented knowledge, attitude and practice of medical students and interns of the King Abdulaziz University, Jeddah and the adoption of a research-intervention educational program. RMJ. 2013;38(4):432-439.

24. Shahab F, Ali MA, Hussain $H$. Involvement and barriers to research amongst students of Khyber Medical College. J Postgrad Med Inst. 2013;27(3):297-302.

25. Althubaiti A. Information bias in health research: definition, pitfalls, and adjustment methods. Journal of Multidisciplinary Healthcare. 2016;9:211-217. doi:10.2147/JMDH.S104807.

26. Tamim HM, Al-Kadri HM, Zamakhshary MF, Al-Alwan IA, Al-Moamary MS, Tamim RM, Al-Sayyari AA. Research as a requirement in a problem-based learning medical curriculum in Saudi Arabia. Saudi Medical Journal. 2012;33(11):1241-1243.

\section{Acknowledgments}

A debt of gratitude is owed to Dr. Ahmed A. Al-Kuwaiti, Deanship of Quality and Academic Accreditation, University of Dammam, Dammam, Saudi Arabia for providing us with the permission to use the students' attitude towards research (SAR) scale.

Conflict of Interest Statement at Funding

The Authors have no funding, financial relationships or conflicts of interest to disclose.

Author Contributions

Conception and design the work/idea, Analysis and interpretation of data, Critical revision of the manuscript, Approval of the final version: AA. Collect data / obtaining results, Write the manuscript: BAM, DAB.

Cite as:

Althubaiti A, Al Muqbil B, Al Buraikan A. Assessment of Medical Students' Attitudes Towards Research and Perceived Barriers. Int J Med Students. 2017;5(3):95-98. 